\title{
Surgical Treatment of Myocardial Infarction and its Complications
}

\author{
A. Hadi Hakki, M.D., F.R.C.S.(C) \\ St. Petersburg, Florida
}

DOI: http://dx.doi.org/10.5915/23-4-15428

\begin{abstract}
The indications and surgical management of patients with acute myocardial infarctions and its complications are discussed. As with any emergency operation, the risk is higher than that of elective cases, thus each patient has to be addressed individually. Improved surgical techniques and myocardial protection has improved the overall survival of these patients. Further clinical investigational research is underway to clearly outline the ideal method of treatment in such patients.
\end{abstract}

Key words: Myocardial infarction, surgical treatment

The treatment of cardiogenic shock is based on the concept of a reversibly injured myocardium. The myocardial infarction (MI) per se is not generally accepted as an indication for an operation. Correction of demand/supply imbalance should be the aim of treatment.

\section{Indications}

In general, in patients with unstable angina, or postmyocardial infarction angina that are not amenable to percutaneous transcoronary angioplasty (PTCA)/thrombolysis therapy, emergency surgical revascularization is a clear indication.

Berg from Spokane, Washington, has employed emergency operations for infarction for several years. ${ }^{1}$ In his series, patients with acute myocardial infarction (MI) were immediately hospitalized and

From the Department of Surgery

Bayfront Medical Center

St. Petersburg, Florida

Reprint Requests: A. Hadi Hakki, M.D.

666 6th Street South

St. Petersburg, FL 33701 operated upon with institution of cardiopulmonary bypass (CB) within six hours of MI. There were only five deaths. Follow up studies through three years and ten months, showed one death (four months after surgery).

Loop et al, reported only one operative death and one late death in a group of 31 patients operated upon within six hours of the diagnosis of acute myocardial infarction. In an average follow up period of 19 months, 25 of 29 surviving patients were in the New York Heart Association (NYHA) Functional Class I. ${ }^{2}$

Acute mechanical complications following acute myocardial infarction is another indication for surgical intervention in an acute clinical setting. These include ventricular septal defect, ruptured papillary muscle causing severe mitral regurgitation, and myocardial rupture. ${ }^{3,4}$

Occasionally, ventricular tachyarrhythmias refractory to all conventional modes of medical therapy may persist following acute myocardial infarction posing a dangerous threat to life. Coronary revascularization surgery with or without resection of left ventricular aneurysm has been effective in many instances. ${ }^{5}$

Intra-aortic balloon pump (IABP) is an important and relatively safe adjunct in the management of patients with post infarction refractory angina and 
mechanical complications. ${ }^{6}$ It has been shown to be very effective in achieving dramatic hemodynamic improvement during support even in patients with severe left ventricular power failure. The criteria in making a decision concerning the indication for urgent revascularization surgery include hemodynamic and clinical stability, IABP dependence, and angiographic factors requiring careful analysis for an appropriate well-guided decision. ${ }^{7,8}$

\section{Management and discussion}

The identifiable syndrome of unstable angina has been shown to be associated with an increased incidence of subsequent acute myocardial infarction and death." The clinical definition for unstable angina pectoris proposed by the National Randomized Study Group consists of:

1. One or more prolonged episodes of chest pain at rest

2. Documented ST/T wave electrocardiographic changes of ischemia during one or more episodes of pain.

3. Acute myocardial infarction excluded by assessing serial EKG tracing and CPK myocardial band isoenzymes. ${ }^{10,11}$

IABP has been an effective tool in addition to pharmacological management in resolving unstable myocardial ischemia allowing safe angiographic study and early revascularization surgery. ${ }^{12-14}$ In patients with post-infarction cardiogenic shock, IABP counterpulsation has been shown capable of reversing the shock syndrome in approximately $75 \%$ of patients. $^{15,16}$ Definitive therapy to improve oxygen delivery to the ischemic myocardium is often necessary to improve survival. ${ }^{17,18}$

The incidence of VSD following acute myocardial infarction is $1.3-2 \%$. The hemodynamic imbalance created is due to shunting of fully oxygenated blood into the lesser circulation which, depending on the size of the VSD, may approach the cardiac output. A vicious cycle ensues, caused by increased left ventricular filling capable of stretching the infarcted area, causing further reduction in the efficacy of left ventricular contraction. The intent of the operation is to close the VSD, resect the wall, and revascularize the coronary arteries as deemed applicable. If cardiogenic shock is present, surgical repair is required within two weeks of infarction, with significantly increased surgical risk. ${ }^{19,20}$ Surgical repair of anteriorly located VSD has been associated with steadily improving results whereas morbidity and mortality with posteriorly located defect repair remains substantial."

The most important factor influencing survival is related to the time interval between acute infarction, the development of VSD and surgery. It has been well documented that approaching the VSD through left ventriculostomy in the infarcted area significantly improved results. ${ }^{20,21}$ Again IABP is of significant benefit in the surgical management, particularly in unstable patients with severe cardiogenic shock. ${ }^{22}$ Various reports in the literature have indicated an overall survival of near $50 \% .^{23-25}$ The results of surgical repair in most series is steadily improving. A $57 \%$ survival has been reported on 14 patients with acquired VSD and cardiogenic shock treated initially with IABP and subsequently by surgical VSD closure. ${ }^{19,24,25}$

Papillary muscle rupture causing acute mitral regurgitation is a relatively rare complication of myocardial infarction, accounting for approximately $1 \%$ of deaths from infarction. ${ }^{20,26}$ Chordae tendineae support both leaflets from each papillary muscle, thus disruption of an entire muscle would involve both leaflets, leading to massive regurgitation. The papillary muscle involved in the majority of reported cases is the posterior papillary muscle and most commonly associated with an inferoposterior infarct. The resultant acute mitral regurgitation presents as a sudden appearance of an atypical systolic murmer and abrupt clinical deterioration, leading to severe left ventricular failure and frequently cardiogenic shock. ${ }^{26}$

The outcome is directly proportional to the condition of the remaining myocardial muscle mass and its ability to generate adequate stroke volume. The mortality of this complication has been reported as $70 \%$ within 24 hours of the development of the murmur and near $90 \%$ within two weeks. ${ }^{27}$ As in VSD, papillary muscle rupture usually occurs within 2-10 days following infarction.

In the MGH experience, 15 of 18 patients operated upon three months or more after myocardial infarction for papillary muscle rupture survived long term. ${ }^{21}$ Thus, when possible, patients with papillary muscle rupture and left ventricular failure are best managed by medical therapy and IABP assistance with surgery at a later period. However, inpatients in cardiogenic shock with or without hemodynamic instability, urgent surgical intervention may be life saving.

Rupture of the free wall of the ventricle has been reported to account for $10 \%$ of deaths from acute myocardial infarction which is second only to cardiogenic shock and arrhytimias as a cause of death. ${ }^{48}$ It usually occurs within two weeks of the infarct and most commonly has been associated with anterior wall infarction. Rupture of the free wall of the left ventricule results in hemorrhage into the pericardial space and abrupt hemodynamic deterioration, resulting from cardiac tamponade within a short interval following rupture. An occasional patient may survive for several hours or even longer if the rupture is contained, resulting in a false aneurysm.

Earlier reports on surgical intervention were not 
encouraging. ${ }^{29}$ Subsequent reports of surgical repair of rupture of heart in patients where the diagnosis was made earlier has been associated with significant salvage. ${ }^{2,31}$ Concomitant coronary artery revascularization may benefit myocardial contractility in areas other than that involved in the rupture. However, it may be impractical due to a deteriorating clinical condition of the patient. Although rupture of the heart frequently results in rapid demise, successful surgical therapy requires:

1. Early diagnosis and rapid transport to the operating room.

2. Pericardiocentesis may be life saving in patients with severe cardiac tamponade.

3. Circulatory assistance in the form of IABP and/or ventricular assist devices particularly in patients with extensive infarction and pump failure.

\section{Summary}

Once significant myocardial infarction has occurred, surgery is best postponed unless post infarction angina or complications develop. The aim of the operation is to expeditiously revascularize the compromised vessel(s) after optimal medical therapy. An emergency operation may preclude the use of the internal mammary artery as a conduit. Although operations for the complications of acute myocardial infarction carry a high mortality rate, the benefits outweigh the risks.

\section{References}

1. Berg R Jr, Kendall RW, Duvoisin E, et al: Acute myocardial infarction. A surgical emergency. J Thorac Cardiovasc Surg 1975; 70:432-9.

2. Loop PF, Cheavenchai C, Sheldon WC, et al: Emergency myocardial infarction. Chest 1974; 66:478-82.

3. Donahoo JS, Brawley RK, Taylor, et al: Factors influencing survival following post-infarction ventricular septal defects. Ann Thorac Surg 1975; 19:648-53.

4. Friedman HS: Cardiac rupture following myocardial infarction: A review. Cardiol Digest 1973; 8:10-6.

5. Yashar J, Yashar JJ, Witoszka M, Kitzes DC, Simeone FA: The treatment of patients with recurrent ventricular fibrillation. Am J Surg 1977; 133:453-7.

6. Mundth ED. Assisted circulation. Gibbon's Surgery Of The Chest. 1983; 1490-1515.

7. Jones EL, Waites TF, Craver JM, et al: Coronary bypass for relief of persistent pain following acute myocardial infarction. Ann Thorac Surg 1981; 32:33-43.

8. Hochberg MS, Parsonnet V, Gielchinsky I, et al: Timing of coronary revascularization after acute myocardial infarcion. J Thorac Cardiovasc Surg
1984; 88:914-20.

9. Gazes PC, Mobley EM, Faris HM, Duncan RC, Humphrey GB. Preinfarction (unstable) angina. A prospective study-ten year follow up. Circulation 1973; 48:331-7.

10. Hutter AM Jr, Russell RO Jr, Resnekog L, et al: Unstable angina pectoris. National randomized study of surgical vs. medical therapy. In Volumes 1,2 and 3: Vessel Disease. Circulation 1977; 56 (Suppl 3):60.

11. Russel RO Jr, Resnekog L, Wolk M, et al: Unstable angina pectoris: National cooperative study group to compare surgical and medical therapy. Am J Cardiol 1979; 44(1):112-7.

12. Mundth ED, Buckely MJ, Daggett WM, et al: Intraaortic balloon pump assistance and early surgery in cardiogenic shock. Adv Cardiol 1975. 15:159-67.

13. Weinraub RM, Aroesty JM, Paulin S, et al: Medically refractory unstable angina pectoris. Long-term follow-up of patients undergoing intra-aortic balloon counterpulsation and operation. Am J Cardiol 1979; 43:877-82.

14. Harris PL, Woollard K, Bartoli A, Makey AR: The management of impending myocardial infarction using coronary artery bypass grafting and an intra-aortic balloon pump. J Cardiovase Surg 1980; 21:405-8.

15. Bolooki $\mathrm{H}$ : Indications for use of intra-aortic balloon pump. Clinical Application of IntraAortic Balloon Pumping. Revised 2nd Edition 1984. Fururo Publishers.

16. Dewood AM, Notske RN, Hensley GR, et al: Intraaortic balloon counterpulsation with or without reperfusion for myocardial infarction shock. Circulation 1980; 61:1105-12.

17. Dilley RB, Ross J Jr, Berstein EF: Serial hemodynamics during intra-aortic balloon counterpulsation for cardiogenic shock Circulation 1973; 48 (Suppl 3):99-104.

18. Mundth ED. Surgical treatment of cardiogenic shock and of acute mechanical complications following myocardial infarction. In: Rahimtoola SH, ed, Coronary Bypass Surgery. Philadelphia: PA Davis Co, 1977: 241-64.

19. Donahoo JS, Brawley RK, Taylor D, et al: Factors influencing survival following postinfarction ventricular septal defects. Ann Thorac Surg 1975; 19:648-53.

20. Daggett WM, Mundth ED, Gold HK, et al: Early repair of ventricular septal defect complicating inferior myocardial infarction. Circulation 1974; 49,50: 111-2.

21. Buckley MJ, Mundth ED, Daggett WM, et al: Surgical management of ventricular septal defects and mitral regurgitation complicating acute myocardial infarction. Ann Thorac Surg 1973; 16:598-609. 
22. Mundth ED. Mechanical and surgical interventions for the reduction of myocardial ischemia. Circulation 1976; 53 (Suppl 1):176-83.

23. Deweese JA, Moss AJ, Yu PN. Infarctectomy and closure of ventricular septal rupture following myocardial infarction. Circulation 1972; 45(suppls); 97-101.

24. Lufschanowski R, Anagelini P, Del Rio C, et al: Ventricular septal rupture secondary to myocardial infarction. Chest 1974, 65:59-63.

25. Pickering BN, And Clelan WP: Ventricular septal defects due to acute myocardial infarction. J Cardiovasc Surg 1974, 15:88-90.

26. Sanders RJ, Neuberger KJ, and Ravin A: Rupture of papillary muscles: Occurrence of rupture of posterior muscle in posterior myocardial infarction. Dis Chest 1957, 31:316-23.

27. Friedberg CK: Diseases of The Heart,
Philadelphia; WB Saudners, 1969, 851-7.

28. Naeim F, DeLa Maza LM, and Robbins SL: Cardiac rupture during myocardial infarction. A review of 44 cases. Circulation 1972, 45:1231-9.

29. Lillehei CW, Lande AJ, Rossman WR, et al: Surgical management of myocardial infarction: Some promising concepts utilizing revascularization, mechanical circulatory assistance, operative treatment of severe complications and cardiac replacement. Circulation 1969; 39:IV-315.

30. Fitzgibbon GM, Hooper GD, and Heggtgeit HA: Successful surgical treatment of postinfarction external cardiac rupture. $J$ Thorac Cardiovasc Surg 1972; 63:622-30.

31. Montegut FJ Jr: Left ventricular rupture secondry to myocardial infarction, report of survival with surgical repair. Ann Thorac Surg 1972; 14:75-8. 